\title{
Duration of maternal breast-feeding in the Dominican Republic ${ }^{1}$
}

\author{
Leonelo E. Bautista ${ }^{2}$
}

ABSTRACT

The study reported here explored the influence of maternal, health care, pregnancy, and childrelated factors upon the duration of total breast-feeding (DTBF) in the Dominican Republic. The data for the study, which included 1984 mother-child pairs representative of the Dominican population, came from the National Health Survey of 1991. The child in each of the mother-child pairs was the mother's last-born child who had been breast-fed and was less than 3 years of age at the time of the survey. Interviews with the mothers were used to collect information about the duration of breast-feeding and the factors studied (including maternal age, urban/rural residence, parity, mother's socioeconomic status, maternal education, maternal employment, mother's desire for pregnancy, type of delivery, place of delivery, the type of health worker attending the delivery, the child's sex, the child's birth weight, the time elapsed between delivery and initiation of breast-feeding, the child's age at complete weaning, and the child's age at the time of the survey).

The child's risk of complete weaning at different ages was calculated using the life table method, and the independent effect of each of the study variables was estimated using Cox's regression model. The median DTBF was 7 months. The risk that a child would be completely weaned (the relative rate of complete weaning, or RRCW) was found to be higher among children who received foods other than breast milk and water while still breast-feeding (RRCW $=$ 8.56; 95\% CI $=4.25-17.20$ ), whose mothers had some university education ( $R R C W=1.48$; $95 \% C I=1.24-1.77)$, who began breast-feeding a day or more after delivery $(R R C W=1.25$; $95 \% C I=1.11-1.40)$, who were born in either public health institutions ( $R R C W=1.62 ; 95 \%$ $C I=1.24-2.11)$ or private health institutions ( $R R C W=2.19 ; 95 \% C I=1.65-2.91)$, and who were the first-born of mothers with low socioeconomic status (RRCW $=1.80 ; 95 \%$ $C I=1.45-2.24)$. According to the study results, the country's breast-feeding programs should give special attention to mothers with university educations, those giving birth in private health facilities, and those with low socioeconomic status giving birth to their first child, since these groups tended to breast-feed their children for relatively short periods of time. Also, breast-feeding promotion strategies should stress the importance of delaying the introduction of foods other than breast milk into the child's diet, as this appears to be the one factor having the greatest adverse effect on the duration of breast-feeding.

1 This article has been published in Spanish in the Boletín de la Oficina Sanitaria Panamericana, Vol. 120, No. 5, May 1996, pp. 414-424, with the title "Duración de la lactancia materna en la República Dominicana."

2 Center for Social and Demographic Studies, Santo Domingo, Dominican Republic. Mailing address: Facultad de Salud, Departamento de Salud Pública, Universidad Industrial de Santander, Carrera 32, No. 29-31, 3er. Piso, Bucaramanga, Colombia.
The duration of breast-feeding (DBF) largely determines how much this form of feeding has a favorable influence on infectious disease prevention (1), child development (2), and child survival (3). Study of factors determining DBF is important, because the success of nutrition programs de- pends on identification of factors susceptible to intervention that can serve as the basis for designing and implementing such programs (4). The study of specific populations is also worthwhile; for although there are regional similarities, considerable heterogeneity is known to exist between the coun- 
tries in any given region with regard to DBF and its determining factors $(5,6)$.

Although a number of studies have been done on maternal breast-feeding in the Dominican Republic (7-10), none pinpointed the factors influencing DBF. Also, all but one estimated DBF without considering that DBF was incomplete for those children who were breast-feeding at the time of the survey, and so the estimates could understate actual DBF. The only study that estimated DBF with an appropriate method (10) was conducted among a selected population of women from various cities who gave birth in public hospitals.

In the current study, data drawn from the Dominican Republic National Demographic and Health Survey (DR-DHS) conducted in 1991 (8) were assessed by survival analysis to identify possible sociodemographic, medical care, pregnancy, and infant characteristics influencing DBF.

\section{MATERIALS AND METHODS}

The DR-DHS was part of the Demographic and Health Surveys Program implemented in a number of different countries since 1984 by the Resource Development Institute and the Population Council, with funding provided by the United States Agency for International Development (USAID).

The DR-DHS study population consisted of 7142 women from a multistage, stratified, probabilistic cluster sample. The sample was designed to be representative of women of reproductive age (from 15 to 49 years) in each of the country's eight health regions, as well as in both urban and rural areas. As an initial step, primary sampling units were selected. Such units, containing an average of 80 households each, are normally used for purposes of census supervision. The units were selected systematically in proportion to the number of households in each one. Subsequently, the household count was updated in each selected unit; and, depending on the health region, a fixed number of 40 to
50 households was randomly selected within each unit. Selection of the units and households was performed separately and independently for each urban and rural area, as well as for each of the country's health regions. Using data from this survey (8), a nonconcurrent cohort study was conducted.

Data regarding initiation and duration of breast-feeding among children born over the preceding five years were gathered through interviews with study mothers. As breast-feeding rarely continues more than three years, only mothers with breast-fed children under 36 months old and their last-born breast-fed child were selected for inclusion in the study.

The duration of total breast-feeding (DTBF) was defined as the child's age (in months) at the time of complete weaning, regardless of when consumption of other foods began (11). For children who had died or were still being breast-fed at the time of the survey, the DTBF was considered equal to the child's age at death or at the time of the survey, but for analytical purposes these were treated as rightcensored observations (12).

The independent variables studied included certain sociodemographic characteristics of the mother (age at delivery, education, urban or rural residence, socioeconomic status, parity, and year of the child's birth). Other independent variables relating to health care during pregnancy included the number of prenatal checkups, the personnel in charge of checkups, the type of institution where the delivery took place, the personnel attending the birth, whether or not the mother desired the pregnancy, and the time of initiation of breast-feeding. Study variables relating to the nature of the pregnancy included illnesses during pregnancy (early- and late-gestation vaginal bleeding, placenta previa, high blood pressure, cardiopathies, diabetes, tuberculosis, renal disease, liver disease, or tumors). Other variables included the type of delivery and the child's sex, birth weight, and age at the time of the survey.
To determine the mother's socioeconomic status, each household article possessed by the family was assigned a score based on its market price. The family scores were then ranked from lowest to highest and divided into terciles corresponding to "low," "medium," and "high" socioeconomic levels for purposes of the study.

The conditional risk of complete weaning at each month of age (the probability that a child being breastfed at the beginning of a given month would be completely weaned during that month) and the cumulative risk of complete weaning (the probability of having been completely weaned in the period from the start of breast-feeding to the end of each month of age) were estimated using the life table method (13). As the original sampling design did not assign each woman of reproductive age the same probability of being included in the study, the risks of weaning were weighted in order to obtain valid estimates for the population of the Dominican Republic as a whole. To accomplish this, each observation was multiplied by the inverse of each woman's selection probability, the results being compiled in accordance with the duration of breastfeeding. The selection probabilities for each woman were estimated in the original survey (8). The median DTBF was used as a summary measure.

The effect of the independent variables on DTBF was estimated using the relative rate of complete weaning (RRCW); that is, the quotient of the incidence density among those mothers exposed to a factor and the incidence density among those not thus exposed. For each variable, the RRCW was obtained by exponentiating its regression coefficient, estimated from a proportional hazards model (14).

In addition, since the average time period preceding an event equals the reciprocal of the event's incidence density (15), the duration of breast-feeding in a group of participants may be estimated as the reciprocal of the rate of complete weaning in that group. Accordingly, the reciprocal of the RRCW was used to estimate the relative DTBF 
(how much greater the DTBF was in the group of unexposed mothers than it was in the group of exposed mothers). In this way, each variable's effects were shown not only as a ratio between rates of complete weaning (RRCW), but also as a comparison between durations of breast-feeding.

The independent effect of each variable on DTBF was estimated using a Cox multiple regression model (14). Unweighted data were used in the multiple regression, as the intent was not to obtain national averages but rather to identify associations between DTBF and various risk factors. The degree of statistical significance of the variables included in the model was calculated using Wald's test (16) and the score test (16). The introduction of foods other than water into the child's diet was modeled as a time-dependent variable (17).

To assess whether the relative rates for the variables included in the model were constant over time (assumption of proportional hazards), estimates of survival time $\left(S_{t}\right)$ were obtained for the strata of each variable, and the negative natural logarithms of these estimates $\left(-\ln \left(-\ln S_{t}\right)\right)$ were calculated and plotted against time. When the data satisfy the proportional hazards assumption, the curves of $-\ln \left(-\ln S_{t}\right)$ against time of the strata for each risk factor are parallel (18).

\section{RESULTS}

Our study of 1984 mother-child pairs included primarily mothers who were young (75\% were under age 30$)$, of low parity $(73 \%$ had three children or less), with little education (65\% had no formal education or only primary schooling), and low employment (70\% had no paying job). Only a fifth of the children studied were over 2 years old.

As Table 1 indicates, during the first year of life the maximum conditional risks of complete weaning were observed at 3 months (17.2\%), 6 months (13.4\%), and 12 months (19.3\%). When cumulative risks were considered, it was found that $22.1 \%$ of the children had already been completely weaned after 3 months, $46.4 \%$ after 6 months, and $65.1 \%$ after 12 months. The median DTBF was seven months.

As shown in Table 2, univariate analysis found the DTBF to be associated with several of the sociodemographic characteristics studied. It was longer among mothers age 35 and older as well as among those with higher parity (four or more children). Also, it was shorter among mothers with urban residences, with medium or high socioeconomic levels, and with secondary or university educations. However, the DTBF was not found to be associated with the mother's employment status or with the child's age at the time of the survey.

With regard to medical care during pregnancy (Table 3), the univariate analysis indicated that the DTBF was shorter when the number of prenatal consultations exceeded four, when the prenatal checkups were conducted by nurses, when the mothers gave birth in public or private hospitals, and when the mothers began breast-feeding days (rather than hours) after delivery. On the other hand, the DTBF increased significantly and progressively as the degree of academic preparation of the health professional attending the delivery declined.

Overall, mothers who reported any pregnancy-related diseases and those who had Cesarean deliveries stopped breast-feeding sooner than those who did not (Table 4). However, those who said they never wished to have children and those who would have preferred to delay pregnancy breast-fed longer than those who said they had desired the pregnancy. Neither the sex nor the birth weights of the children were found to be associated with the DTBF.

The results of the multivariate analysis (Table 5) showed that, regardless of the effects of other factors, the introduction of foods other than breast milk and water into a child's diet had the most pronounced effect on the DTBF. Among children who received food supplements, the DTBF was $11.7 \%$ of what it was for those who did
TABLE 1. Conditional and cumulative rates of complete weaning during the first 3 years of life for children in the study sample's mother-child pairs. Dominican Republic, 1991

\begin{tabular}{|c|c|c|c|}
\hline $\begin{array}{c}\text { Age } \\
\text { interval } \\
\text { (months) }\end{array}$ & $\begin{array}{c}\text { Conditional } \\
\text { risk of } \\
\text { complete } \\
\text { weaning (\%) }\end{array}$ & $\begin{array}{l}\text { Cumulative } \\
\text { risk of } \\
\text { complete } \\
\text { weaning (\%) }\end{array}$ & $\begin{array}{c}95 \% \mathrm{Cl} \text { for } \\
\text { cumulative } \\
\text { risk of } \\
\text { complete } \\
\text { weaning }\end{array}$ \\
\hline$[0-1]$ & 5.5 & 0.0 & - \\
\hline [1-2] & 8.1 & 5.5 & $4.5-6.6$ \\
\hline [2-3] & 10.2 & 13.2 & $11.6-14.8$ \\
\hline [3-4] & 17.2 & 22.1 & $20.2-24.0$ \\
\hline [4-5] & 10.6 & 35.5 & $33.2-37.8$ \\
\hline [5-6] & 7.0 & 42.4 & $40.0-44.7$ \\
\hline$[6-7]$ & 13.4 & 46.4 & $44.0-48.8$ \\
\hline [7-8] & 5.0 & 53.6 & $51.2-56.1$ \\
\hline [8-9] & 6.4 & 55.9 & $53.5-58.4$ \\
\hline [9-10] & 6.7 & 58.7 & $56.3-61.2$ \\
\hline [10-11] & 3.0 & 61.5 & $59.1-64.0$ \\
\hline [11-12] & 6.5 & 62.7 & $60.2-65.1$ \\
\hline [12-13] & 19.3 & 65.1 & $62.6-67.5$ \\
\hline [13-14] & 3.8 & 71.8 & $69.4-74.2$ \\
\hline [14-15] & 13.9 & 72.9 & $70.0-75.3$ \\
\hline [15-16] & 10.7 & 76.7 & $74.3-79.0$ \\
\hline$[16-17]$ & 4.4 & 79.2 & $76.8-81.5$ \\
\hline [17-18] & 7.4 & 80.1 & $77.8-82.4$ \\
\hline [18-19] & 17.7 & 81.6 & $79.2-83.8$ \\
\hline [19-20] & 19.1 & 84.8 & $82.6-87.0$ \\
\hline [20-21] & 3.8 & 87.7 & $85.6-89.8$ \\
\hline [21-22] & 8.8 & 88.2 & $86.1-90.3$ \\
\hline [22-23] & 1.8 & 89.2 & $87.2-91.3$ \\
\hline [23-24] & 18.6 & 89.4 & $87.4-91.5$ \\
\hline [24-25] & 27.4 & 91.4 & $89.3-93.4$ \\
\hline [25-26] & 13.0 & 93.7 & $91.8-95.7$ \\
\hline [26-27] & 6.3 & 94.6 & $92.6-96.5$ \\
\hline [27-28] & 0.0 & 94.9 & $93.0-96.8$ \\
\hline [28-29] & 0.0 & 94.9 & $93.0-96.8$ \\
\hline [29-30] & 22.2 & 94.9 & $93.0-96.8$ \\
\hline [30-31] & 54.6 & 96.0 & $94.0-98.0$ \\
\hline [31-32] & 0.0 & 98.2 & $96.3-100.0$ \\
\hline [32-33] & 0.0 & 98.2 & $96.3-100.0$ \\
\hline [33-34] & 0.0 & 98.2 & $96.3-100.0$ \\
\hline [34-35] & 0.0 & 98.2 & $96.3-100.0$ \\
\hline
\end{tabular}

$95 \% \mathrm{Cl}=95 \%$ confidence interval.

not. Thus, the former were completely weaned more than eight times sooner than the latter.

The Table 5 data also indicate that mothers with some university education completely weaned their children sooner than those with less education, the first group's adjusted relative DTBF being only $67.6 \%$ of the second group's. The adjusted relative DTBFs were also lower for mothers who gave birth in public or private hospitals $(61.7 \%$ and $45.7 \%$, respectively, of that for mothers who gave birth at home), 
TABLE 2. The median duration of total breast-feeding (MDTBF) in months, the relative rate of complete weaning (RRCW) with its $95 \%$ confidence interval, and the relative duration of total breast-feeding $\times 100$ (RDTBF $\times 100$ ) for study children under 3 years of age, by sociodemographic characteristics of the mother. Dominican Republic, 1991

\begin{tabular}{|c|c|c|c|c|}
\hline $\begin{array}{l}\text { Sociodemographic } \\
\text { characteristics }\end{array}$ & MDTBF & $\begin{array}{l}\text { Crude } \\
\text { RRCW }\end{array}$ & $\begin{array}{l}95 \% \mathrm{Cl} \\
\text { for RRCW }\end{array}$ & $\begin{array}{l}\text { Crude } \\
\text { RDTBF }\end{array}$ \\
\hline \multicolumn{5}{|l|}{ Maternal age in years } \\
\hline$\leq 19$ & 10 & 1.00 & - & 100.0 \\
\hline $20-24$ & 8 & 1.06 & $0.80-1.24$ & 94.3 \\
\hline $25-29$ & 8 & 1.08 & $0.91-1.28$ & 92.6 \\
\hline $30-34$ & 7 & 1.01 & $0.83-1.23$ & 99.0 \\
\hline $35-39$ & 12 & 0.76 & $0.57-1.00$ & 131.6 \\
\hline $40-49$ & 16 & 0.43 & $0.26-0.71$ & 232.6 \\
\hline \multicolumn{5}{|l|}{ Area of residence } \\
\hline Rural & 13 & 1.00 & - & 100.0 \\
\hline Urban & 8 & 1.58 & $1.41-1.77$ & 63.3 \\
\hline \multicolumn{5}{|l|}{ Parity } \\
\hline 1 & 8 & 1.00 & - & 100.0 \\
\hline 2 & 8 & 0.81 & $0.70-0.94$ & 123.5 \\
\hline 3 & 8 & 0.78 & $0.67-0.91$ & 128.5 \\
\hline 4 & 12 & 0.56 & $0.45-0.68$ & 178.6 \\
\hline$\geq 5$ & 16 & 0.41 & $0.34-0.49$ & 243.9 \\
\hline \multicolumn{5}{|l|}{ Socioeconomic level } \\
\hline Low & 15 & 1.00 & - & 100.0 \\
\hline Medium & 8 & 1.94 & $1.70-2.22$ & 51.5 \\
\hline High & 6 & 2.48 & $2.16-2.86$ & 40.3 \\
\hline \multicolumn{5}{|l|}{ Educational level } \\
\hline None & 17 & 1.00 & - & 100.0 \\
\hline Primary & 11 & 1.49 & $1.21-1.84$ & 67.1 \\
\hline Secondary & 8 & 2.19 & $1.76-2.74$ & 45.7 \\
\hline University & 5 & 3.57 & $2.77-4.61$ & 28.0 \\
\hline \multicolumn{5}{|l|}{ Employment status } \\
\hline Unemployed & 9 & 1.00 & - & 100.0 \\
\hline Employed & 7 & 1.09 & $0.97-1.23$ & 91.7 \\
\hline \multicolumn{5}{|l|}{$\begin{array}{l}\text { Age of child at time } \\
\text { of survey (years) }\end{array}$} \\
\hline 0 & 9 & 1.00 & - & 100.0 \\
\hline 1 & 8 & 1.07 & $0.93-1.24$ & 93.5 \\
\hline 2 & 9 & 1.01 & $0.86-1.19$ & 98.6 \\
\hline
\end{tabular}

$95 \% \mathrm{Cl}=95 \%$ confidence interval.

as well as for mothers who initiated breast-feeding one or more days after delivery $(80.0 \%$ of that for mothers who breast-fed sooner).

Unexpectedly, the study found that socioeconomic level had different effects on multiparous as opposed to primiparous mothers (see Table 5). Specifically, multiparas with medium and high socioeconomic status had adjusted relative DTBFs that were only about half those of the multiparas with low socioeconomic status. While primiparas with medium and high socioeconomic status also had low DTBFs relative to primiparas with low socioeconomic status, the contrast was less (the two former groups' DTBFs being $85 \%$ and $73 \%$ of the latter group's, respectively).

Conversely, the effect of parity on the DTBF was influenced by socioeconomic level. Among mothers with low socioeconomic status, the adjusted relative DTBF for primiparas was $55.6 \%$ of that for multiparas. However, among mothers with medium and high socioeconomic status the adjusted relative DTBFs for primiparas were $86.2 \%$ and $82.0 \%$, respectively, of that for mul- tiparas. These latter reductions in the DTBF were not statistically significant, in contrast to the interaction between the effects of socioeconomic level and parity on DTBF (score test $=10.15$; degrees of freedom $=2 ; P=0.006$ ).

It should also be noted that the curves of the $-\ln \left(-\ln S_{t}\right)$ as a function of time obtained with the final regression model were parallel for the various strata of each risk factor. This finding suggested that the data satisfied the fundamental assumption of the Cox regression model (18).

\section{DISCUSSION}

The median DTBF found in this study was seven months, and the highest conditional risks of complete weaning were observed after 3,6 , and 12 months of age. Introduction of food supplements differing from breast milk and water was the risk factor having the greatest negative effect on the DTBF. In addition, maternal university education, late initiation of breast-feeding, primiparity combined with low socioeconomic status, and delivery at a health care institution significantly lowered the DTBF.

To date, no estimates of the cumulative risk of complete weaning among Dominican children have been reported. The median DTBF (7 months) found in this study was slightly higher than that reported (6 months) by demographic and health surveys for 1986 and $1991(7,8)$ and more than twice that estimated for 1987 by another study (3 months) (9). These differences could be attributable to the current study's use of survival analysis (13) to estimate DTBF, because other studies did not consider the prospective nature of the data on breast-feeding duration-which could have led to underestimation of the DTBF (13).

As indicated above, the variable most strongly reducing DTBF was introduction of food supplements to the child's diet. Winikoff (19) has obtained similar results with various population groups, and Hill (20) has pointed 
out that introduction of formula is the factor having the greatest impact on early suspension of breast-feeding. However, in interpreting the effect of introducing food supplements on DTBF, it is necessary to consider the reason for such action. If food supplements are introduced for the purpose of preparing the child for complete weaning, it would by definition be associated with a shorter DTBF. In this case, it would be impossible to know the extent to which the DTBF reduction results from an intent to suspend breast-feeding and the extent to which it is an undesirable consequence of the change in feeding behavior.

On the other hand, if the aim of introducing these foods is to supplement the child's diet, this action should be regarded as a risk factor for complete weaning. For most cases in the current study this appears the most probable explanation, since introduction of food supplements occurred, on the average, at 2 months of age, while the median complete weaning time was seven months. It is important to point out that the results of an experimental study (21) show that introduction of food supplements before 6 months of age does not provide any nutritional benefits for the child.

Although the current study found the DTBF to be shorter among mothers having a university education than among those with less education, the effects of education on DTBF as reported in the literature are contradictory. In poor countries, a high educational level has been associated with a shorter DTBF (22-24), although adjusted null effects (19) or increases with educational level (25) have also been detected. On the other hand, in industrialized countries DTBF appears to increase with the mother's educational level $(26,27)$. The prevalence of shorter DTBFs among more educated women from poor countries might be explained by the fact that mothers in the more educated group tend to adopt artificial feeding methods sooner than other mothers.

Regardless of the effect of other variables, women who gave birth in pri-
TABLE 3. The median duration of total breast-feeding (MDTBF) in months, the relative rate of complete weaning (RRCW) with its $95 \%$ confidence interval, and the relative duration of total breast-feeding $\times 100($ RDTBF $\times 100)$ for study children under 3 years of age, by characteristics of health care during pregnancy. Dominican Republic, 1991

\begin{tabular}{|c|c|c|c|c|}
\hline $\begin{array}{l}\text { Characteristics of } \\
\text { health care }\end{array}$ & MDTBF & $\begin{array}{l}\text { Crude } \\
\text { RRCW }\end{array}$ & $\begin{array}{l}95 \% \mathrm{Cl} \\
\text { for RRCW }\end{array}$ & $\begin{array}{l}\text { Crude } \\
\text { RDTBF }\end{array}$ \\
\hline \multicolumn{5}{|c|}{ Number of prenatal checkups } \\
\hline $0-4$ & 14 & 1.00 & - & 100.0 \\
\hline $5-7$ & 8 & 1.50 & $1.28-1.75$ & 66.7 \\
\hline $8-9$ & 8 & 1.73 & $1.47-2.04$ & 57.8 \\
\hline $10+$ & 7 & 1.94 & $1.64-2.31$ & 51.5 \\
\hline \multicolumn{5}{|c|}{$\begin{array}{l}\text { Person conducting prenatal } \\
\text { checkups }\end{array}$} \\
\hline Physician & 13 & 1.00 & - & 100.0 \\
\hline Nurse & 7 & 1.63 & $1.46-1.83$ & 61.3 \\
\hline Other & 15 & 0.71 & $0.51-1.00$ & 140.8 \\
\hline \multicolumn{5}{|l|}{ Place of delivery } \\
\hline Home/other & 17 & 1.00 & - & 100.0 \\
\hline Public facility & 11 & 2.09 & $1.61-2.71$ & 47.8 \\
\hline Private facility & 5 & 3.73 & $2.85-4.87$ & 26.8 \\
\hline \multicolumn{5}{|l|}{ Initiation of breast-feeding } \\
\hline $\begin{array}{l}\text { Within minutes/hours } \\
\text { of delivery }\end{array}$ & 10 & 1.00 & - & 100.0 \\
\hline Within days of delivery & 7 & 1.35 & $1.20-1.51$ & 74.1 \\
\hline \multicolumn{5}{|c|}{$\begin{array}{l}\text { Individual who attended the } \\
\text { delivery }\end{array}$} \\
\hline Obstetrician & 7 & 1.00 & - & 100.0 \\
\hline General practitioner & 11 & 0.71 & $0.63-0.80$ & 140.8 \\
\hline Nurse & 13 & 0.62 & $0.48-0.80$ & 161.3 \\
\hline Midwife & 17 & 0.35 & $0.27-0.45$ & 285.7 \\
\hline
\end{tabular}

$95 \% \mathrm{Cl}=95 \%$ confidence interval.

TABLE 4. The median duration of total breast-feeding (MDTBF) in months, the relative rate of complete weaning (RRCW) with its $95 \%$ confidence interval, and the relative duration of total breast-feeding $\times 100$ (RDTBF $\times 100)$ for study children under 3 years of age, by characteristics of the pregnancy, sex of the child, and birth weight. Dominican Republic, 1991

\begin{tabular}{|c|c|c|c|c|}
\hline $\begin{array}{c}\text { Characteristics of pregnancy } \\
\text { and child }\end{array}$ & MDTBF & $\begin{array}{l}\text { Crude } \\
\text { RRCW }\end{array}$ & $\begin{array}{l}95 \% \mathrm{Cl} \\
\text { for RRCW }\end{array}$ & $\begin{array}{l}\text { Crude } \\
\text { RDTBF }\end{array}$ \\
\hline \multicolumn{5}{|l|}{ Illness during pregnancy } \\
\hline No & 10 & 1.00 & - & 100.0 \\
\hline Yes & 7 & 1.31 & $1.12-1.53$ & 76.3 \\
\hline \multicolumn{5}{|l|}{ Type of delivery } \\
\hline Natural & 11 & 1.00 & - & 100.0 \\
\hline Cesarean & 7 & 1.55 & $1.36-1.76$ & 64.5 \\
\hline \multicolumn{5}{|l|}{ Desire for pregnancy } \\
\hline Then & 8 & 1.00 & - & 100.0 \\
\hline Later & 11 & 0.88 & $0.77-1.00$ & 113.6 \\
\hline Never & 14 & 0.68 & $0.58-0.79$ & 147.1 \\
\hline \multicolumn{5}{|l|}{ Sex } \\
\hline Male & 9 & 1.00 & - & 100.0 \\
\hline Female & 9 & 0.98 & $0.88-1.09$ & 102.0 \\
\hline \multicolumn{5}{|l|}{ Birth weight } \\
\hline$\geq 2500 \mathrm{~g}$ & 11 & 1.00 & - & 100.0 \\
\hline$<2500 \mathrm{~g}$ & 9 & 0.93 & $0.75-1.14$ & 107.5 \\
\hline
\end{tabular}

$95 \% \mathrm{Cl}=95 \%$ confidence interval. 
TABLE 5. The relative rate of complete weaning (RRCW) with its $95 \%$ confidence interval and the relative duration of total breast-feeding (RDTBF) adjusted for sociodemographic characteristics of the mother, characteristics of health care during pregnancy, characteristics of the pregnancy, sex of the child, and birth weight. Dominican Republic, 1991

\begin{tabular}{|c|c|c|c|}
\hline Characteristic & RRCW & $\begin{array}{l}95 \% \mathrm{Cl} \\
\text { for RRCW }\end{array}$ & $\begin{array}{l}\text { Adjusted } \\
\text { RDTBF }\end{array}$ \\
\hline \multicolumn{4}{|l|}{ Introduction of foods } \\
\hline No & 1.00 & - & 100.0 \\
\hline Yes & 8.56 & $4.25-17.2$ & 11.7 \\
\hline \multicolumn{4}{|l|}{ Formal education } \\
\hline None through high school & 1.00 & - & 100.0 \\
\hline University & 1.48 & $1.24-1.77$ & 67.6 \\
\hline \multicolumn{4}{|l|}{ Place of delivery } \\
\hline Home/other & 1.00 & - & 100.0 \\
\hline Public facility & 1.62 & $1.24-2.11$ & 61.7 \\
\hline Private facility & 2.19 & $1.65-2.91$ & 45.7 \\
\hline \multicolumn{4}{|l|}{$\begin{array}{l}\text { Time at which breast-feeding } \\
\text { was initiated }\end{array}$} \\
\hline Within minutes/hours of delivery & 1.00 & - & 100.0 \\
\hline Within days of delivery & 1.25 & $1.11-1.40$ & 80.0 \\
\hline \multicolumn{4}{|l|}{ Socioeconomic level } \\
\hline \multicolumn{4}{|l|}{ Multiparas } \\
\hline Low & 1.00 & - & 100.0 \\
\hline Medium & 1.84 & $1.56-2.17$ & 54.3 \\
\hline High & 2.02 & $1.68-2.42$ & 49.5 \\
\hline \multicolumn{4}{|l|}{ Primiparas } \\
\hline Low & 1.00 & - & 100.0 \\
\hline Medium & 1.18 & $0.95-1.51$ & 84.7 \\
\hline High & 1.37 & $1.06-1.76$ & 73.0 \\
\hline \multicolumn{4}{|l|}{ Parity } \\
\hline \multicolumn{4}{|l|}{ Low socioeconomic level } \\
\hline Multiparas & 1.00 & - & 100.0 \\
\hline Primiparas & 1.80 & $1.45-2.24$ & 55.6 \\
\hline \multicolumn{4}{|l|}{ Medium socioeconomic level } \\
\hline Multiparas & 1.00 & - & 100.0 \\
\hline Primiparas & 1.16 & $0.95-1.40$ & 86.2 \\
\hline \multicolumn{4}{|l|}{ High socioeconomic level } \\
\hline Multiparas & 1.00 & - & 100.0 \\
\hline Primiparas & 1.22 & $0.99-1.50$ & 82.0 \\
\hline
\end{tabular}

vate or public hospitals tended to breast-feed their children less time than those who delivered at home. A similar tendency has been observed among mothers in Bangkok (28) and Bogotá (29). In addition, one study (19) found that irrespective of other factors, delivery attended by a physician was associated with a shorter DTBF. This suggests that the delivery site's effect might result from the influence of modern maternal care practices on initiation and continuation of breastfeeding $(6,30,31)$, given that conventional hospital care can interfere with establishment of the bonding between a mother and her child that is necessary for successful breast-feeding (32).
This could occur despite the fact that promotion and supply of breast milk substitutes were prohibited in the Dominican Republic following a "babyfriendly hospitals" initiative (31).

As numerous studies have indicated $(28,30,33,34)$, early initiation of breast-feeding was associated with an increased DTBF. Moreover, a positive effect that rooming-in has on the DTBF has been attributed to early contact between the mother and her child (35). This effect is so important that WHO and the United Nations Children's Fund (UNICEF) recommend application of rooming-in models in all maternity wards (31). The shorter DTBF observed among mothers who delay the start of breast-feeding could be due to fewer opportunities for breast-feeding and also to production of a lower volume of milk in the absence of the stimulus provided by sucking.

As already noted, the effect of socioeconomic level on the DTBF depended on the mother's parity. While in primiparous mothers the DTBF decreased slightly with increased socioeconomic level, in multiparous women it dropped sharply. According to these findings, the DTBF was not significantly associated with parity among mothers with medium or high socioeconomic status, while primiparas with low socioeconomic status had a DTBF that was only $56 \%$ of that of 
multiparas in the same socioeconomic stratum. This type of interaction has not previously been reported.

As this study was not designed to evaluate the interaction between parity and socioeconomic status, it is difficult to determine whether that interaction is the result of physiologic or sociocultural factors. It is possible that the lower DTBF in primiparas was due to the lower reserve of body fat in these women compared to multiparas. This difference in body fat reserves could be less marked among mothers with medium or high socioeconomic levels, as a result of their better nutritional status. It is also true that primiparas have no breast-feeding experience, which could explain their tendency to breast-feed for a shorter time than multiparas. This lack of experience could be partially offset among mothers of medium and high socioeconomic status, as a result of their better access to information on breast-feeding. Unfortunately, it was not possible to explore these hypotheses for lack of data on either the mothers' nutritional status or their level of knowledge about breast-feeding.
More generally, the findings of this study could be partly due to the effect of selection bias, since $21.6 \%$ of the women selected in the original sample were not interviewed (8). Lack of information about the characteristics of these nonparticipants makes it impossible to evaluate either the magnitude or the direction of possible biases. However, since maternal mortality was very low, one may assume that no significant bias in the estimation of the DTBF and its associations was introduced by including in the study only those mothers who were alive at the time of the original survey.

It is unlikely that the results obtained are attributable to information errors. Even though data on breastfeeding were dependent on maternal recall, the recall period was short $(80 \%$ of the children were less than 2 years old, and the mothers were asked only about the most recent child). Reports should also be noted that indicate the quality of the information gathered in national health surveys tends to be good (36) and that mothers are able to recall accurately how long they breastfed their children (37).

\section{REFERENCES}

1. Goldman AS, Garza C, Nichols BL, Goldblum RM. Immunologic factors in human milk during the first year of lactation. J Pediatr 1982; 100:563-567.

2. Nylander G, Lindemann R, Helsing E, Bendvold E. Unsupplemented breastfeeding in the maternity ward: positive long-term effects. Acta Obstet Gynecol Scand 1991;70:205-209.

3. Victoria CG, Smith PG, Vaughan JP, et al. Evidence for protection by breast-feeding against infant deaths from infectious diseases in Brazil. Lancet 1987;2:319-322.

4. Tognetti J. Evaluating breastfeeding promotion programmes. In: Jelliffe DB, Jelliffe EFP. Programmes to promote breastfeeding. New York: Oxford University Press; 1988:405-419.

5. Pérez-Escamilla R. Breastfeeding in Africa and the Latin American and Caribbean region: the potential role of urbanization. J Trop Pediatr 1994;40:137-143.

6. Winikoff B, Laukaran VH. Breast feeding and bottle feeding controversies in the developing world: evidence from a study in four countries. Soc Sci Med 1989;29:859-868.
7. República Dominicana, Secretaría de Estado de Salud Pública y Asistencia Social, Consejo Nacional de Población y Familia; Institute for Resource Development; Westinghouse. Encuesta demográfica y de salud 1986 (DHS-86). Santo Domingo: CONAPOFA; 1987.

8. República Dominicana, Instituto de Estudios de Población y Desarrollo, Oficina Nacional opment; Macro International Inc. Encuesta demográfica y de salud 1991. Santo Domingo: PROFAMILIA; 1992.

9. Gómez E, Montero R, Canario M. Patrones de lactancia materna en el Distrito Nacional de la República Dominicana. In: República Dominicana, Centro Nacional de Investigación en Salud Materno Infantil. Estado actual de la lactancia materna en la República Dominicana. Santo Domingo: CENISMI; 1987.

10. Ogando E, Romero H, Soriano G. Monitoreo del efecto de las políticas económicas y sociales en el bienestar infantil 1988-1991. Santo Domingo: Centro Nacional de Investigación en Salud Materno Infantil, Oficina Nacional de Planifide Planificación; Institute for Resource Devel-
Since Cox's model properly reflected the nature of the data, it can be assumed that the findings did not depend on the type of statistical analysis performed.

Overall, the results obtained indicate that breast-feeding promotion programs in the Dominican Republic should focus on mothers with university-level education, those who give birth in private health facilities, and primiparas with relatively low socioeconomic status, since these groups of women tend to breast-feed their children for relatively short periods of time. In regard to their strategies, these programs should stress the importance of delaying the introduction of food supplements to the child's diet, as this appears to be the factor that has the greatest negative impact on breast-feeding duration.

Acknowledgment. This study was financed by the Institute for Resource Development (IRD), Macro/International. cación; Fondo de las Naciones Unidas para la Infancia; 1992.

11. Labbok M, Krasovec K. Toward consistency in breastfeeding definitions. Stud Fam Plann 1990;21:226-230.

12. Kahn HA, Sempos CT. Follow-up studies: life tables. In: Kahn HA, Sempos CT. Statistical methods in epidemiology. New York: Oxford University Press; 1989:168-205.

13. Collect D. Modelling survival data in medical research. London: Chapman and Hall; 1994: 15-24.

14. Collect D. Modelling survival data in medical research. London: Chapman and Hall; 1994: 53-106.

15. Rothman K. Modern epidemiology. Boston: Little Brown; 1986:23-29.

16. Clayton D, Hills M. Statistical models in epidemiology. Oxford: Oxford University Press; 1993:96-109.

17. Thomas DC. Statistical methods for analyzing effects of temporal patterns of exposure on cancer risks. Scand I Work Environ Health 1983; 9:353-366. 
18. Harrell FE Jr, Lee KL. Verifying assumptions of the Cox proportional hazards model. In: Proceedings of the Eleventh Annual SAS User's Group International Conference, 1986. Cary, NC: SAS Institute; 1986.

19. Winikoff B. Summary. In: Winikoff B, Castle MA, Laukaran VH. Feeding infants in four societies: causes and consequences of mothers' choices. New York: Greenwood Press; 1988:227-246.

20. Hill PD. Predictors of breast-feeding duration among WIC and non-WIC mothers. Public Health Nurs 1991;8:46-52.

21. Cohen RJ, Brown KH, Canahuati J, Rivera LL, Dewey KG. Effects of age of introduction of complementary foods on infant breast milk intake and growth: a randomised intervention study in Honduras. Lancet 1994;344:288-293.

22. Meftuh AB, Tapsoba LP, Lamounier JA. Breastfeeding practices in Ethiopian women in southern California. Indian J Pediatr 1991;58: 349-356.

23. Manderson L. "These are modern times": infant feeding practice in Peninsular Malaysia. Soc Sci Med 1984;18:47-57.

24. Forman MR. Review of research on the factors associated with choice and duration of infant feeding in less-developed countries. Pediatrics 1984;74:667-694.

25. Monteiro CA, Zúñiga HP, Benicio MH, Rea MF. Breast-feeding patterns and socioeconomic status in the city of São Paulo. J Trop Pediatr 1988;34:186-192.

26. Michaelsen KF, Larsen PS, Thomsen BL, Samuelson G. The Copenhagen cohort study on infant nutrition and growth: duration of breast feeding and influencing factors. Acto Paediatr 1994;83:565-571.

27. Vestermark V, Hogdall CK, Plenov G, Birch $\mathrm{M}$, Toftager-Larsen $\mathrm{K}$. The duration of breastfeeding: a longitudinal prospective study in Denmark. Scand J Soc Med 1991;19:105-109.

28. Winikoff B, Durongdej S, Cerf BJ. Infant feeding in Bangkok, Thailand. In: Winikoff B, Castle MA, Laukaran VH. Feeding infants in four societies: causes and consequences of mothers' choices. New York: Greenwood Press; 1988:15-41.

29. Castle MA, Solimano G, Winikoff B, Samper de Paredes B, Romero ME, Morales de Look A. Infant feeding in Bogotá, Colombia. In: Winikoff B, Castle MA, Laukaran VH. Feeding infants in four societies: causes and consequences of mothers' choices. New York: Greenwood Press; 1988:43-66.

30. Winikoff B, Castle MA. The influence of health services on infant feeding. In: Winikoff B, Castle MA, Laukaran VH. Feeding infants in four societies: causes and consequences of mothers' choices. New York: Greenwood Press; 1988 147-164.

31. World Health Organization. Protecting, promoting, and supporting breast-feeding: the special role of maternity services: a joint WHO/UNICEF statement. Int I Gynecol Obstet 1990;31(Suppl):171-183.

32. Hofmeyr GJ, Nikodem VC, Wolman WL, Chalmers BE, Kramer T. Companionship to modify the clinical birth environment: effects on progress and perceptions of labour, and breast-feeding. Br J Obstet Gynaecol 1991;98: 756-764.

33. Salariya EM, Easton PM, Cater JI. Duration of breastfeeding after early initiation and frequent feeding. Lancet 1978;2:1141-1143.

34. Elander G, Lindberg T. Short mother-infant separation during first week of life influences the duration of breastfeeding. Acta Paediatr Scand 1984;73:237-240.

35. Pérez-Escamilla R, Segura Millan S, Pollitt E, Dewey KG. Effect of the maternity ward system on the lactation success of low-income urban Mexican women. Early Hum Dev 1992;31:25-40.

36. Goldman N, Rutstein SO, Singh S. Assessment of the quality of data in 41 WFS surveys: a comparative approach. Voorburg, Netherlands: International Statistics Institute; 1985:5-83.

37. Eaton Evans J, Dugdale AE. Recall by mothers of the birth weights and feeding of their children. Hum Nutr Appl Nutr 1986;40:171-175.

Manuscript received on 25 May 1995. Accepted for publication, following revision, in Spanish in the Boletin de la Oficina Sanitaria Panamericana on 22 February 1996 and in English in the Revista Panamericana de Salud Pública/Pan American Journal of Public Health on 2 April 1996.

RESUMEN En el presente estudio se reanalizaron los datos de la Encuesta Nacional de Salud de la República Dominicana, realizada en 1991, con el fin de identificar las características sociodemográficas, de la atención médica, del embarazo y el niño que influyen sobre

Duración de la lactancia materna en la República Dominicana la duración de la lactancia materna total (DLMT). Se estudió una muestra de 1984 parejas madre-hijo representativa de la población nacional. De los hijos de cada madre, solo se incluyó al último niño nacido vivo, que era amamantado y menor de 3 años de edad en el momento de la encuesta. Los datos sobre la DLMT y los factores estudiados se recabaron entrevistando a las madres (incluidos la edad, tipo de residencia, paridad, nivel socioeconómico, educación, empleo y deseo de procrear de la madre, tipo de parto y lugar en que se produjo, tipo de trabajador de la salud que lo atendió, sexo y peso al nacer del hijo, tiempo transcurrido entre el parto y el inicio de la lactancia materna, y edad del niño al cesar la lactancia y en el momento de realizarse la encuesta). El riesgo de haber sido destetado a distintas edades se calculó por el método de la tabla de vida y el efecto independiente de cada variable de interés se estimó por medio de un modelo de regresión de Cox. La duración mediana de la lactancia materna total fue 7 meses y la tasa relativa de destete (TRD) fue más alta en los niños ablactados (TRD = 8,56; IC95\%: 4,25-17,20), los de madres universitarias (TRD = 1,48; IC95\%: 1,24-1,77), los que comenzaron a mamar tardíamente (TRD =1,25; IC95\%: $1,11-1,40)$, los que nacieron en instituciones públicas (TRD =1,62; IC95\%: 1,24-2,11) y privadas (TRD $=2,19$; IC95\%: 1,65-2,91), y en los de madres primíparas de nivel socioeconómico bajo (TRD = 1,80; IC95\%: 1,45-2,24). Los programas de lactancia materna del país deben prestar especial atención a las madres con educación universitaria, a las que dan a luz en hospitales privados y a las primíparas de nivel socioeconómico bajo, ya que estas mujeres tienden a amamantar a sus hijos durante períodos relativamente cortos. Dentro de las estrategias de los programas de promoción de la lactancia materna habría que subrayar la importancia que reviste el retraso de la ablactación, pues este parece ser el factor que mayor impacto ejerce en la duración de la lactancia materna. 